\title{
Interaction between the $\mathrm{N}$ - and $\mathrm{C}$-Terminal Domains Modulates the Stability and Lipid Binding of Apolipoprotein A-I†
}

\author{
Mao Koyama ${ }^{\ddagger}$, Masafumi Tanaka ${ }^{\ddagger}$, Padmaja Dhanasekaran $\S$, Sissel Lund-Katz $§$, Michael C. \\ Phillips $\$$, and Hiroyuki Saito $\neq,{ }^{*}$ \\ ¥Department of Biophysical Chemistry, Kobe Pharmaceutical University, Kobe 658-8558, Japan \\ $\S$ Division of GI/Nutrition/Hepatology, The Children's Hospital of Philadelphia, University of \\ Pennsylvania School of Medicine, Philadelphia, Pennsylvania 19104-4318
}

\section{Abstract}

The tertiary structure of human and mouse apolipoprotein A-I (apoA-I) are comprised of an Nterminal helix bundle and independently folded $\mathrm{C}$-terminal domain. To define the possible intramolecular interaction between the $\mathrm{N}$ - and $\mathrm{C}$-terminal domains, we examined the effects on protein stability and lipid-binding properties of exchanging either the C-terminal domain or helix between human and mouse apoA-I. Chemical denaturation experiments demonstrated that replacement of the C-terminal domain or helical segment in human apoA-I with the mouse counterparts largely destabilizes the $\mathrm{N}$-terminal helix bundle. Removal of the $\mathrm{C}$-terminal domain or $\alpha$-helix in human apoA-I had a similar effect on the destabilization of the helix bundle against urea denaturation, indicating that the C-terminal helical segment mainly contributes to stabilizing the $\mathrm{N}$ terminal helix bundle structure in the apoA-I molecule. Consistent with this, KI quenching experiments indicated that removal or replacement of the $\mathrm{C}$-terminal domain or helix in human apoAI causes Trp residues in the $\mathrm{N}$-terminal domain to become exposed to solvent. Measurements of the heats of binding to egg phosphatidylcholine (PC) vesicles and the kinetics of solubilization of dimyristoyl PC vesicles demonstrated that the destabilized human $\mathrm{N}$-terminal helix bundle can strongly interact with lipid without the hydrophobic C-terminal helix. In addition, site-specific labeling of the $\mathrm{N}$ - and $\mathrm{C}$-terminal helices by acrylodan to probe the conformational stability and the spatial proximity of the two domains indicated that the $\mathrm{C}$-terminal helix is located near the $\mathrm{N}$-terminal helix bundle, leading to a relatively less solvent-exposed, more organized conformation of the Cterminal domain. Taken together, these results suggest that interaction between the $\mathrm{N}$ - and C-terminal tertiary structure domains in apoA-I modulates the stability and lipid-binding properties of the Nterminal helix bundle.

\begin{abstract}
Apolipoprotein A-I (apoA-I) is the major protein of plasma high density lipoprotein (HDL) and functions as a critical mediator in reverse cholesterol transport, a process by which excess cholesterol in peripheral cells is transferred via HDL to the liver for catabolism (1-3). Although apoA-I exists primarily in a lipid-bound state on HDL particles in plasma, lipid-free apoA-I is known to be a physiologically relevant acceptor of cell-derived cholesterol via ATP-binding cassette transporter A1 (ABCA1) $(4,5)$. The interaction of lipid-free apoA-I with functional ABCA1 results in the lipidation of apoA-I and formation of nascent HDL particles, in which a multi-step mechanism seems to be involved with this reaction process (6-8).
\end{abstract}

\footnotetext{
$\dagger$ This work was supported by NIH grant HL22633, Grant-in-Aid for Scientific Research from JSPS (19590048), and Takeda Science Foundation.

*To whom correspondence should be addressed: Dr. Hiroyuki Saito, Department of Biophysical Chemistry, Kobe Pharmaceutical University, 4-19-1 Motoyamakitamachi, Higashinada-ku, Kobe 658-8558, Japan, Tel: +81-78-441-7539, Fax: +81-78-441-7541, saito@kobepharma-u.ac.jp.
} 
ApoA-I is a 243-residue polypeptide that contains characteristic 11- and 22-residue repeats of amphipathic $\alpha$-helices (9). The $\mathrm{N}$ - and $\mathrm{C}$-terminal helical regions in the apoA-I molecule contribute to the strong lipid-binding properties of this protein (10-12) as well as the conformational stability in solution $(13,14)$. It has been demonstrated recently that the apoAI molecule folds into two tertiary structure domains, comprising an $\mathrm{N}$-terminal $\alpha$-helix bundle spanning residues 1-187 and a separate less organized C-terminal region spanning the remainder of the molecule (15-17). The ability to fold into two domains seems to be a general feature of the apoA-I molecule regardless of the species of origin (18). However, the links between the two-domain structure and the function of apoA-I remain to be established (19).

Although the x-ray crystal structure of the lipid-free apoA-I clearly demonstrates the compactly folded, highly ordered two-domain structure (17), it appears that the true conformation in solution is more flexible and less organized than the crystal state $(20,21)$. The $\alpha$-helix content of approximately $82 \%$ found in the crystal structure is much higher than the approximately $50 \%$ found for monomeric apoA-I in solution $(11,22)$. Indeed, a recent electron paramagnetic resonance spectroscopy study showed that the $\mathrm{N}$-terminal region (residues 1-98) is heterogeneous in its secondary structure, including a short segment of $\beta$-strand structure (23). Interestingly, this $\beta$-strand structure is similar in length to the $\beta$-strand observed in the $\mathrm{C}$ terminus (24), suggesting the potential of these regions to participate in intra- or inter-domain interaction.

It has been proposed that the interactions between the $\mathrm{N}$ - and C-terminal segments in apoA-I are involved in maintaining the stability of the lipid-free conformation $(13,14,16,25)$.

Fluorescence resonance energy transfer (FRET) studies demonstrated that the C-terminal residues 190 and 232 are in close proximity to the four Trp residues in the $\mathrm{N}$-terminal domain of apoA-I $(26,27)$. In agreement with this, the homology modeling based on cross-link distance constraints predicts that the $\mathrm{N}$ - and C-termini of lipid-free apoA-I are situated in relatively close proximity (16). Such interactions between the $\mathrm{N}$ - and $\mathrm{C}$-terminal segments also seem to modulate the lipid-binding ability and ABCA1-mediated cholesterol efflux by apoA-I (14, 28-30). However, the detailed molecular nature of the $\mathrm{N}$ - and $\mathrm{C}$-terminal interaction in apoA$\mathrm{I}$ is unknown to date.

Here, we examined the effects of truncation or substitution of the C-terminal domain or helical segment on the protein stability and lipid-binding properties to define the intramolecular interaction between the $\mathrm{N}$ - and C-terminal domains in apoA-I. In addition, we used site-specific fluorescence labeling of the $\mathrm{N}$ - and $\mathrm{C}$-terminal helices to probe the conformational stability and the spatial proximity of the two domains. The results suggest that the $\mathrm{C}$-terminal helix is located near the N-terminal helix bundle, modulating the conformational stability and lipidbinding properties of apoA-I.

\section{EXPERIMENTAL PROCEDURES}

\section{Proteins and Peptide}

Human/mouse apoA-I hybrid molecules were engineered using the Stratagene (La Jolla, CA) "domain-swap" protocol (18). The mutations in human apoA-I to introduce cysteine residue into Val-53 or Phe-229 were made using the QuikChange site-directed mutagenesis kit (Stratagene). Human and mouse wild type (WT) apoA-I and engineered mutants were expressed and purified as described $(15,18)$. The apoA-I preparations were at least $95 \%$ pure as assessed by SDS-PAGE. The C-terminal apoA-I 220-241/F229C peptide was synthesized at Sigma Genosys (Hokkaido, Japan) with an acetylated N-terminus and an amidated Cterminus. Peptide purity was verified by analytical HPLC ( $>97 \%)$ and mass spectrometry. In all experiments, apoA-I variants and peptide were freshly dialyzed from $6 \mathrm{M}$ guanidine 
hydrochloride $(\mathrm{GdnHCl})$ solution $(+1 \% \beta$-mercaptoethanol for the cysteine-containing mutants) into the appropriate buffer before use.

\section{Site-specific Acrylodan (Ac) Labeling}

Cysteine-containing apoA-I variants or peptide were incubated with 10-fold molar excess of tris(2-carboxyethyl)phosphine hydrochloride (Pierce, Rockford, IL) for $1 \mathrm{~h}$ to reduce the sulfhydryl group. The $10 \mathrm{mM}$ stock solution of 6-acryloyl-2-dimethylaminonaphthalene (acrylodan; Molecular Probes, Inc., Eugene, OR) in dimethylformamide was added so that a final molar ratio of probe to protein was 10:1 (or 3:1 for peptide). The reaction mixtures were then stirred at room temperature for $3 \mathrm{~h}$ in the dark. Unreacted acrylodan was removed by extensive dialysis at $4{ }^{\circ} \mathrm{C}$ in Tris buffer $(10 \mathrm{mM}$ Tris, $150 \mathrm{mM} \mathrm{NaCl}, 1 \mathrm{mM}$ EDTA, $0.02 \%$ $\mathrm{NaN}_{3}, \mathrm{pH}$ 7.4). The degree of labeling was determined using the extinction coefficient for acrylodan of $19,200 \mathrm{M}^{-1} \mathrm{~cm}^{-1}$ at $391 \mathrm{~nm}$ and found to be over $90 \%$.

\section{Preparation of SUV}

Small unilamellar vesicles (SUVs) were prepared as described $(11,14)$. Briefly, a film of egg phosphatidylcholine (PC) on the wall of a glass tube was dried under vacuum overnight. The lipid was then hydrated in Tris buffer and sonicated on ice under nitrogen. After removing titanium debris, the samples were centrifuged in a Beckman TLA 110 rotor for $2 \mathrm{~h}$ at $4{ }^{\circ} \mathrm{C}$ at $51,000 \mathrm{rpm}$ to separate any remaining large vesicles. The PC concentration of SUV was determined using an enzymatic assay kit from Wako Pure Chemicals (Osaka, Japan).

\section{Circular Dichroism (CD) Spectroscopy}

Far-UV CD spectra were recorded from 185 to $260 \mathrm{~nm}$ at $25^{\circ} \mathrm{C}$ using an Aviv 62DS spectropolarimeter. After dialysis from $6 \mathrm{M} \mathrm{GdnHCl}$ solution, the apoA-I sample was diluted to $25-50 \mu \mathrm{g} / \mathrm{ml}$ in $10 \mathrm{mM}$ sodium phosphate buffer ( $\mathrm{pH} 7.4$ ) and the CD spectrum was obtained. The results were corrected by subtracting the buffer baseline. The $\alpha$-helix content was calculated from the molar ellipticity at $222 \mathrm{~nm}$, as described (31). For monitoring chemical denaturation, proteins at a concentration of $50 \mu \mathrm{g} / \mathrm{ml}$ were incubated overnight at $4{ }^{\circ} \mathrm{C}$ with $\mathrm{GdnHCl}$ or urea at various concentrations. $K_{\mathrm{D}}$ at a given denaturant concentration was calculated from the ellipticity values and, the free energy of denaturation, $\Delta G_{\mathrm{D}}{ }^{\circ}$, the midpoint of denaturation, $D_{1 / 2}$, and $m$ value which reflects the cooperativity of denaturation in the transition region, were determined by the linear equation, $\Delta G_{\mathrm{D}}=\Delta G_{\mathrm{D}}{ }^{\circ}-m$ [denaturant], where $\Delta G_{\mathrm{D}}=-R T \ln K_{\mathrm{D}}(14,31)$.

\section{Fluorescence Measurements}

Fluorescence measurements were carried out with a Hitachi F-7000 fluorescence spectrophotometer at $25^{\circ} \mathrm{C}$ in Tris buffer ( $\mathrm{pH}$ 7.4). Trp emission fluorescence of proteins at a concentration of $25 \mu \mathrm{g} / \mathrm{ml}$ was recorded from 300 to $420 \mathrm{~nm}$ using a $295 \mathrm{~nm}$ excitation wavelength to avoid tyrosine fluorescence. Acrylodan emission fluorescence of proteins or peptide ( $5-25 \mu \mathrm{g} / \mathrm{ml}$ ) was collected from 380 to $600 \mathrm{~nm}$ using a $360 \mathrm{~nm}$ excitation wavelength. For chemical denaturation experiments, $\Delta G_{\mathrm{D}}{ }^{\circ}, D_{1 / 2}$, and $m$ value were determined by monitoring the change in wavelength of maximum fluorescence (WMF) of intrinsic Trp residues (15) or the generalized polarization (GP) of acrylodan (32). The GP value is given by GP $=\left(I_{\mathrm{B}}-I_{\mathrm{R}}\right) /\left(I_{\mathrm{B}}+I_{\mathrm{R}}\right)$, where $I_{\mathrm{B}}$ and $I_{\mathrm{R}}$ are the emission intensities at the blue (450 or 460 $\mathrm{nm})$ and red $(520 \mathrm{~nm})$ edges of the emission spectrum, respectively. In fluorescence quenching experiments, the Trp or acrylodan emission spectra of proteins were recorded at increasing concentrations of $\mathrm{KI}(0-0.56 \mathrm{M})$ using a $5 \mathrm{M}$ stock solution containing $1 \mathrm{mM} \mathrm{NaS}_{2} \mathrm{O}_{3}$ to prevent the formation of iodine. After correction for dilution, the integrated fluorescence intensities were plotted according to the Stern-Volmer equation, $F_{0} / F=1+K_{\mathrm{SV}}[\mathrm{KI}]$, where $F_{0}$ and $F$ are the fluorescence intensities in the absence and presence of quencher, respectively, and $K_{\mathrm{sv}}$ is 
the Stern-Volmer constant. Quenching parameters were obtained by fitting to the modified Stern-Volmer equation, $F_{0}\left(F_{0}-F\right)=1 / f_{\mathrm{a}}+1 / f_{\mathrm{a}} K_{\mathrm{sV}}[\mathrm{KI}]$, where $f_{\mathrm{a}}$ is the fraction of Trp residues accessible to the quencher. Steady-state fluorescence anisotropy of acrylodan was measured with excitation at $360 \mathrm{~nm}$ and emission at $485 \mathrm{~nm}$, as described (33). ANS fluorescence spectra were collected from 400 to $600 \mathrm{~nm}$ at an excitation wavelength of $395 \mathrm{~nm}$ in the presence of $50 \mu \mathrm{g} / \mathrm{ml}$ protein and an excess of ANS $(250 \mu \mathrm{M})(15)$.

For FRET experiments, the emission spectra of acrylodan-labeled and unlabeled apoA-I variants were measured from 300 to $600 \mathrm{~nm}$ with excitation of $295 \mathrm{~nm}$. FRET efficiency $(E)$ was calculated according to $E=1-F_{\mathrm{DA}} / F_{\mathrm{D}}$, where $F_{\mathrm{DA}}$ is the fluorescence intensity of the donor with acrylodan attached and $F_{\mathrm{D}}$ is the fluorescence intensity of the donor lacking acrylodan. The FRET distance $(R)$ was calculated according to $E=R_{0}^{6} /\left(R_{0}^{6}+R^{6}\right)$, where $R_{0}$ is the Förster radius for energy transfer from Trp to acylodan in a protein (2.7 nm) (34).

\section{DMPC clearance assay}

The kinetics of solubilization of DMPC multilamellar vesicles by the apoA-I variants were measured by monitoring the time-dependent decrease in turbidity $(18,35)$. DMPC vesicles extruded through a 200-nm filter were mixed with apoA-I samples to a final volume of $600 \mu \mathrm{l}$ in a cuvette, and incubated for $15 \mathrm{~min}$ at $24.6{ }^{\circ} \mathrm{C}$. Sample light scattering intensity was monitored at $325 \mathrm{~nm}$ on a Shimadzu UV-2450 spectrophotometer.

\section{Isothermal Titration Calorimetry (ITC) Measurements}

Heats of apoA-I binding to SUV were measured with a MicroCal MCS isothermal titration calorimeter at $25^{\circ} \mathrm{C}(11,36)$. To measure the enthalpy of binding at a low surface concentration, apoA-I solutions were injected into SUV in the cell at a PC-to-protein molar ratio > 10,000 where the injected protein binds completely to the SUV surface. Heat of dilution was determined in control experiment by injecting apoA-I solution into buffer, and was subtracted from the heat determined in the corresponding apoA-I-SUV binding experiments.

\section{RESULTS}

\section{Urea Denaturation of Human/Mouse apoA-I Hybrid Molecules}

We have demonstrated previously that both human and mouse apoA-I adopt a two-domain structure, comprising an $\mathrm{N}$-terminal helix bundle domain and a separate $\mathrm{C}$-terminal domain (18). In addition, exchanging the C-terminal domains between human and mouse apoA-I to create human/mouse hybrid molecules affected the stability of the N-terminal helix bundle against $\mathrm{GdnHCl}$, suggesting an energetic contribution of interactions between the $\mathrm{N}$ - and $\mathrm{C}$ terminal domains to the overall stability of apoA-I (18). To follow up this possible interaction between the $\mathrm{N}$ - and $\mathrm{C}$-terminal domains in apoA-I, we examined the effects of exchanging the $\mathrm{C}$-terminal domain or $\alpha$-helix between human and mouse apoA-I on the protein stability against urea denaturation. The electrostatic interactions between amino acids are shielded by $\mathrm{GdnHCl}$, whereas uncharged urea has no effect on the electrostatic interactions (37). Thus, we can estimate the contribution of the electrostatic interactions to the protein stability by comparing denaturation behaviors in both denaturants.

As shown in Table 1, replacement of the C-terminal domain or $\alpha$-helix in human apoA-I with the mouse counterparts to create the human(h)/mouse(m) hybrid apoA-I molecules, $\mathrm{h}(1-189) /$ $\mathrm{m}(187-240)$ and $\mathrm{h}(1-220) / \mathrm{m}(218-240)$, results in no change in $\alpha$-helix content (18). However, both apoA-I hybrid molecules exhibited greatly decreased stability against urea denaturation compared to human WT apoA-I as monitored by molar ellipticity (Figure 1A) and Trp fluorescence (Figure 1B). Comparison of the thermodynamic parameters such as the free energy and midpoint of denaturation between apoA-I $\mathrm{h}(1-189) / \mathrm{m}(187-240)$ and $\mathrm{h}(1-220) / \mathrm{m}$ 
(218-240) revealed that the substitutions of the C-terminal domain or $\alpha$-helix in human apoAI by the mouse counterparts have similar destabilizing effects on the protein (Table 1). It should be noted that since all Trp residues are located in the $\mathrm{N}$-terminal helix bundle domain (positions $8,50,72$, and 108), Trp fluorescence reflects the conformational change of the $\mathrm{N}$-terminal helix bundle. Thus, it follows that the substitution of the human C-terminal $\alpha$-helix with the equivalent mouse $\mathrm{C}$-terminal segment mainly contributes to the destabilization of the human $\mathrm{N}$-terminal helix bundle by the mouse C-terminal domain.

\section{Effects of Removal or Disruption of the C-Terminal Helix on Chemical Denaturation of Human ApoA-I}

To further examine the contribution of the C-terminal $\alpha$-helix to the stability of the $\mathrm{N}$-terminal helix bundle in human apoA-I, we used the C-terminally truncated mutants, apoA-I 1-222 and 1-189 (15) or proline-inserted mutant, apoA-I L230P/L223P/Y236P in which the C-terminal $\alpha$-helical structure is disrupted $(14,38)$. Previous studies showed that such removal or disruption of the C-terminal $\alpha$-helix in apoA-I has no effect on the stability of the N-terminal helix bundle against $\mathrm{GdnHCl}$ denaturation $(14,15)$. In contrast, these mutations in the Cterminal $\alpha$-helix destabilized the $\mathrm{N}$-terminal helix bundle against urea denaturation as monitored by Trp fluorescence (Figure 2A). Comparison of the free energies of denaturation by $\mathrm{GdnHCl}$ and urea (Figure 2B) clearly demonstrates that the C-terminal $\alpha$-helix stabilizes the $\mathrm{N}$-terminal helix bundle of apoA-I against urea denaturation, but not against $\mathrm{GdnHCl}$ denaturation. This suggests that electrostatic interactions are involved in the stabilization of the N-terminal helix bundle by the C-terminal $\alpha$-helix. Similar destabilization of the Cterminally truncated mutants against urea denaturation was also observed by monitoring the molar ellipticity (data not shown).

\section{KI Quenching and ANS Binding of Human ApoA-I C-Terminal Mutants}

We next performed KI quenching of Trp fluorescence and ANS binding experiments for the apoA-I variants to monitor the tertiary structural change induced by the C-terminal truncation or substitution. As shown in Table 2, significant increases in $K_{\mathrm{SV}}$ values for the C-terminally truncated or substituted mutants were observed compared to WT apoA-I, indicating that Trp residues in these $\mathrm{C}$-terminal mutants are more exposed to the aqueous phase. ANS fluorescence results indicate that there is decreased hydrophobic surface exposure in the $\mathrm{C}$-terminal mutants due to removal or replacement of the hydrophobic human C-terminal domain or $\alpha$-helix with the more polar and disordered mouse counterparts (18).

\section{Lipid-Binding Properties of Human/Mouse ApoA-I Hybrid Molecules}

To assess the lipid-binding properties of the human/mouse hybrid apoA-I, we compared their abilities to solubilize DMPC vesicles (DMPC clearance assay) (18,35,39). As shown in Figure $3 \mathrm{~A}$, the concentration-dependence curves for human WT and its isolated $\mathrm{N}$ - and $\mathrm{C}$-terminal domains (residues 1-189 and 190-243) demonstrate that the $\mathrm{N}$-terminal domain is much less effective than WT apoA-I in solubilizing DMPC vesicles whereas the C-terminal domain is extremely effective (18). Interestingly, apoA-I $\mathrm{h}(1-189) / \mathrm{m}(187-240)$ and $\mathrm{h}(1-220) / \mathrm{m}(218-$ 240) hybrid molecules displayed intermediate efficiencies between human WT and the isolated human $\mathrm{N}$-terminal domain despite the fact that the isolated mouse $\mathrm{C}$-terminal domain (residues 187-240) itself was practically inactive. This suggests that the destabilized human N-terminal domain can interact with lipids effectively without the hydrophobic human C-terminal domain.

We also compared binding enthalpies of the human/mouse hybrid apoA-I to stable egg PC SUV $(11,18)$. As shown in Figure 3B, human WT and its isolated N- and C-terminal domains exhibited large exothermic heats whereas the mouse $\mathrm{C}$-terminal domain exhibited almost no heat (18). However, both apoA-I h(1-189)/m(187-240) and h(1-220)/m(218-240) exhibited much larger exothermic heats compared to the human $\mathrm{N}$-terminal domain, indicating that the 
destabilization of the human $\mathrm{N}$-terminal domain by substituting the $\mathrm{C}$-terminal $\alpha$-helix with the equivalent mouse $\mathrm{C}$-terminal segment promotes its lipid-binding capability.

\section{Acrylodan Fluorescence}

We next employed site-specific labeling of apoA-I by acrylodan to probe the conformational properties and the spatial proximity of the $\mathrm{N}$ - and $\mathrm{C}$-terminal domains in apoA-I. Acrylodan has been used for the site-specific conformational studies of proteins $(26,27,40,41)$ because it has several advantages as a fluorescence probe such as high sensitivity to the solvent environment and relatively low molecular weight. For attachment of acrylodan, we used two Cys-introduced mutants, V53C and F229C apoA-I. V53 and F229 are located in the putative $\mathrm{N}$ - and C-terminal $\alpha$-helices (residues 44-65 and 220-241) of apoA-I, respectively, and our previous study revealed that neither the Cys mutagenesis nor the fluorescence labeling cause discernible changes in the lipid-free structure and lipid interaction of apoA-I (42).

Figure 4 shows the change in acrylodan emission spectra of apoA-I V53C-Ac when incubated at different concentrations of urea (from 0 to $6.4 \mathrm{M}$ ). Significant decreases in fluorescence intensity and red shifts in WMF of acrylodan were observed with increasing concentrations of urea, indicating transfer of the acrylodan molecule from the hydrophobic interior in a folded protein into an aqueous environment $(26,41)$. Such changes in spectroscopic properties of aminoacylnaphthalene derivatives have been described by GP, which is proportional to changes in the emission spectrum $(32,43)$. Since a decrease in GP value signifies an increase in the environment polarity of acrylodan, the difference in denaturation curves for apoA-I V53C-Ac and F229C-Ac monitored by acrylodan GP (Figure 4, inset) reflects the different stabilities of the $\mathrm{N}$ - and $\mathrm{C}$-terminal helices in apoA-I against urea denaturation. As listed in Table 3, thermodynamic parameters of denaturation against $\mathrm{GdnHCl}$ and urea for apoA-I V53C-Ac and F229C-Ac indicate that V53 and F229 have similar stability against GdnHCl whereas V53 is more stable than F229 against urea. This suggests that both the N-and Cterminal helices have comparable conformational stability but the $\mathrm{N}$-terminal helix is stabilized more than the C-terminal helix via electrostatic interactions.

To further characterize the site-specific structure of the two domains, we compared WMF, fluorescence anisotropy, and KI quenching parameters of acrylodan fluorescence for apoA-I V53C-Ac and F229C-Ac (Table 4). The WMF values are 451 and $458 \mathrm{~nm}$ for V53C-Ac and F229C-Ac, respectively, indicating that both the $\mathrm{N}$ - and C-terminal helices are in hydrophobic environments (26). Consistent with this, low $K_{\mathrm{SV}}$ values for both V53C-Ac and F229C-Ac suggest that both regions are shielded from the solvent. Interestingly, acrylodan-labeled Cterminal helical peptide, apoA-I 220-241/F229C-Ac exhibited a much higher WMF value corresponding to polarity in water (26) and higher $K_{\mathrm{SV}}$ value compared to apoA-I F229C-Ac. In addition, fluorescence anisotropy reflecting the motional restriction of acrylodan was much lower in the peptide than in the apoA-I F229C-Ac. Taken together, these results suggest that the C-terminal helical region in the folded apoA-I molecule has a much more organized conformation than in the isolated helical peptide.

Finally, we measured the FRET from the Trp residues located in the N-terminal domain to acrylodan attached in the $\mathrm{N}$ - or $\mathrm{C}$-terminal helices to confirm prior studies showing that the $\mathrm{C}$ terminal segments are in close proximity to the $\mathrm{N}$-terminal domain $(26,27)$. Compared to the unlabeled apoA-I V53C and F229C mutants, there were significant decreases in Trp emission fluorescence at around $335 \mathrm{~nm}$ and the concomitant appearance of an acrylodan fluorescence peak at around $460 \mathrm{~nm}$, indicating the occurrence of FRET from Trp residues to acrylodan in the folded apoA-I (Figures 5A and 5C). Because we monitored FRET at the protein concentration in which apoA-I exists completely as a monomer (44), the observed FRET dominantly comes from intramolecular interactions. The calculated FRET efficiency $(E)$ and average distance $(R)$ between the Trp residues and the acrylodan probe were 0.53 and $2.7 \mathrm{~nm}$ 
for apoA-I V53C-Ac and 0.40 and $2.9 \mathrm{~nm}$ for apoA-I F229C-Ac, respectively, indicating that the acrylodan probe attached at not only the $\mathrm{N}$-terminal helix but also the $\mathrm{C}$-terminal helix is in close proximity to Trp residues in the $\mathrm{N}$-terminal domain. In contrast, after complete unfolding of apoA-I in the presence of $3 \mathrm{M} \mathrm{GdnHCl}$, the difference in the Trp fluorescence between the unlabeled and acrylodan-labeled apoA-I and acrylodan fluorescence peak became remarkably small (Figures 5B and 5D), indicating decreases in FRET due to increased separation of the Trp residues and acrylodan $(E=0.24$ and 0.12 for apoA-I V53C-Ac and F229C-Ac, respectively). For apoA-I V53C-Ac, the proximity of the fluorophores in the primary sequence is likely to cause some FRET even in the presence of denaturant. A similar decrease in FRET for apoA-I F229C-Ac was also observed in the presence of 6M urea (data not shown), suggesting that hydrophobic interaction contributes to the close proximity of the two domains.

\section{DISCUSSION}

The large exchangeable apolipoproteins such as apoA-I and apoE appear to share a common two-domain structure, in which the N-terminal $\sim 70 \%$ of the molecule forms a helix bundle domain and the $\mathrm{C}$-terminal domain exists as a discrete, less organized structure $(15,19)$. Recent studies using the $\mathrm{C}$-terminal truncation variants indicated that this two-domain tertiary structure is also adopted by a new member of the exchangeable apolipoprotein family, apoA-V (45, 46). It is proposed that, in general, the $\mathrm{N}$ - and $\mathrm{C}$-terminal elements in proteins have a tendency to be in contact, playing some special roles in protein folding and function (47). Indeed, it has been demonstrated that the $\mathrm{C}$-terminal domain in apoE4 is in close contact with the $\mathrm{N}$-terminal domain in the lipid-free state as well as on discoidal complexes due to the electrostatic interaction between the two domains (48). Recent cross-linking experiments for the lipidbound conformation of apoA-I on discoidal complexes suggested that the $\mathrm{N}$-terminal end folds back on itself, stabilizing an intermolecular interaction with the hydrophobic C-terminal domain (49). Although the presence of the $\mathrm{N}$ - and $\mathrm{C}$-terminal interaction in the lipid-free apoAI molecule has also been proposed $(13,14,16,23)$, the experimental evidence has not been provided to date.

Our previous study comparing the structural stabilities of the $\mathrm{N}$ - and C-terminal domains in human and mouse apoA-I suggested that the interactions between the $\mathrm{N}$ - and $\mathrm{C}$-terminal domains contribute to the stability of the N-terminal helix bundle domain (18). The results of urea denaturation for the C-terminal truncated or substituted variants of human apoA-I (Figure 1 , Figure 2 and Table 1 ) in this study clearly demonstrate that the C-terminal $\alpha$-helical region (residues 223-243) is primarily responsible for the stabilization of the $\mathrm{N}$-terminal helix bundle by the $\mathrm{C}$-terminal domain. The finding that the disruption of the C-terminal $\alpha$-helix by the praline insertion (L230P/L233P/Y236P) reduced the protein stability against urea denaturation (Figure 2) further indicates that the ability of this region to form $\alpha$-helical structure is critical for the $\mathrm{N}$ - and $\mathrm{C}$-terminal interaction. In addition, comparison of the free energy of denaturation as monitored by Trp fluorescence between $\mathrm{GdnHCl}$ and urea (Figure 2B) suggests that the electrostatic interactions between the $\mathrm{N}$-terminal helix bundle and the $\mathrm{C}$-terminal $\alpha$-helix are involved in this stabilizing effect.

In apoE4, Arg-61 in the N-terminal domain forms a salt-bridge with Glu-255 in the C-terminal domain (50), leading to the less organized and more exposed conformation of the C-terminal domain in apoE4 than occurs in apoE3 $(35,51)$. FRET and electron paramagnetic resonance measurements showed that such domain interaction in apoE4 results in a closer distance between the $\mathrm{N}$ - and $\mathrm{C}$-terminal domains than apoE3 (48). FRET analyses in the previous (26, 27) and the present (Figure 5) studies between Trp residues in the N-terminal domain and acrylodan attached in the $\mathrm{C}$-terminal helix suggest that, like apoE4, the interaction between the $\mathrm{N}$ - and $\mathrm{C}$-terminal domains in apoA-I causes the C-terminal $\alpha$-helix to be in close proximity 
to the N-terminal helix bundle. Although these FRET data can be used to estimate only an average distance due to the presence of four Trp residues in the fluorescence energy donor, the derived average distance between Trp residues and F229C-acrylodan of $2.9 \mathrm{~nm}$ seems to be shorter than the calculated distances from the x-ray crystal structure of lipid-free apoA-I (2.6, 5.6, 3.5, and $3.1 \mathrm{~nm}$ from F229 to W8, W50, W72, and W108, respectively) (17). It is likely that such a close proximity of the two domains in the lipid-free apoA-I results in not only stabilization of the N-terminal helix bundle (Figure 1, Figure 2 and Table 1), but also the relatively less solvent-exposed, more organized conformation of the C-terminal helical region, which is comparable to the $\mathrm{N}$-terminal helix bundle structure (Table 3 and Table 4).

Based on the two-domain tertiary structure of apoA-I, we have proposed a two-step mechanism for binding of apoA-I to a phospholipid surface $(15,19)$. In this model, initial binding step occurs through hydrophobic amphipathic $\alpha$-helices in the C-terminal domain (24), followed by a conformational opening of the $\mathrm{N}$-terminal helix bundle to expose the hydrophobic faces of the amphipathic helices. In the first binding step, the C-terminal $\alpha$-helix appears to separate from the N-terminal domain, perhaps converting helix-helix interactions between the two domains to lipid interactions of the C-terminal helix. This would result in the destabilization of the N-terminal helix bundle, which may trigger the conformational opening of the helix bundle in the second binding step. Interestingly, similar mechanisms by which the initial lipid interaction triggers the conformational opening of the helix bundle structure have been proposed for the lipid binding of apolipophorin III (52) and apoE (53).

Tertiary structural plasticity is thought to be functionally important for apolipoprotein binding to the lipid surface $(54,55)$. Indeed, the inverse correlation between the protein stability and the ability to transform phospholipid vesicles into doscoidal complexes were observed for apolipoprotein III $(56,57)$ and the $\mathrm{N}$-terminal domain of apoE isoforms $(39,58)$. In apoA-I, it was reported that deletion or mutation of both the $\mathrm{N}$ - and $\mathrm{C}$-terminal regions induces the less stable, molten globular-like conformation, possibly facilitating the protein binding to the lipid surface $(14,30)$. It was also demonstrated recently that under acidic conditions, apoA-I increases its $\alpha$-helical content and hydrophobicity thereby promoting the formation of discoidal complexes (59). Consistent with these findings, we demonstrated in the present study that the destabilization of the human $\mathrm{N}$-terminal domain by substituting the $\mathrm{C}$-terminal domain or helical segment with the equivalent mouse counterparts promotes the lipid-binding ability of apoA-I (Figure 3). Thus, given the structural similarity of the N-terminal helix bundle among exchangeable apolipoproteins $(15,19)$, it is conceivable that besides the hydrophobicity and $\alpha$-helix content of the $\mathrm{C}$-terminal domain, the stability of the $\mathrm{N}$-terminal helix bundle regulates the lipid-binding property of apoA-I (18). However, it should be noted that other reports showed that double deletion of the $\mathrm{N}$ - and C-terminal regions reduces or abolishes the lipidbinding ability of apoA-I despite the greatly reduced protein stability $(28,29)$.

Many plasma apolipoproteins such as apoA-I, apoA-II, apoC-II, and apoE display a high susceptibility to form or associate with amyloid fibrils both in vitro and in vivo (60), perhaps due to their partially folded, flexible conformation in the lipid-free state (61). Naturally occurring mutations in human apoA-I associated with hereditary amyloidosis are known to be all localized around the $\mathrm{N}$-terminus of protein (62). Interestingly, in most cases of these mutated apoA-I, the N-terminal fragment is the predominant form of protein found in amyloid fibril deposits (63). Although the structural consequences of these mutations have not been defined yet, these findings suggest the possibility of an unstable $\mathrm{N}$-terminal conformation being associated with mutations in this region. Since the $\mathrm{C}$-terminal domain stabilizes the $\mathrm{N}$-terminal helix bundle structure as shown in this study, it is tempting to speculate that the mutated apoAI may be more susceptible to cleavage of the $\mathrm{C}$-terminal domain, creating an unstable Nterminal fragment of apoA-I which may initiate the formation of amyloid fibrils. Indeed, it was reported that transthyretin-cleaved apoA-I (apoA-I $\Delta 226-243)$ presents an overall 
conformational destabilization and a higher propensity for aggregation compared to intact apoA-I (64). In addition, the fact that many of the mutations associated amyloidosis result in an additional positive charge within the N-terminal domain in apoA-I (62) may suggest an alteration in the electrostatic interaction between the $\mathrm{N}$ - and $\mathrm{C}$-terminal domains in these mutants, leading to the destabilization of the $\mathrm{N}$-terminal helix bundle structure.

In summary, the present study demonstrated that the interaction between the $\mathrm{N}$ - and C-terminal domains in the lipid-free apoA-I causes the C-terminal $\alpha$-helix to be located near the $\mathrm{N}$-terminal helix bundle. Such close proximity of the two domains in apoA-I results in not only stabilization of the $\mathrm{N}$-terminal helix bundle structure, but also in a relatively less solvent-exposed, more organized conformation of the C-terminal helical region. The apoA-I mutations associated with hereditary amyloidosis may alter this domain interaction, resulting in an unstable, partially folded conformation of the $\mathrm{N}$-terminal helix bundle which appears to be a crucial characteristic for the formation of amyloid fibrils.

\section{Abbreviations}

$\begin{array}{ll}\text { ABCA1 } & \text { ATP-binding cassette transporter A1 } \\ \text { Ac } & \text { acrylodan } \\ \text { apoA-I } & \text { apolipoprotein A-I } \\ \text { CD } & \text { circular dichroism } \\ \text { DMPC } & \text { dimyristoylphosphatidylcholine } \\ \text { FRET } & \text { fluorescence resonance energy transfer } \\ \text { GP } & \text { generalized polarization } \\ \text { GdnHCl } & \text { guanidine hydrochloride } \\ \text { HDL } & \text { high density lipoprotein } \\ \text { ITC } & \text { isothermal titration calorimetry } \\ \text { PC } & \text { phosphatidylcholine } \\ \text { SUV } & \text { small unilamellar vesicle } \\ \text { WMF } & \text { wavelength of maximum fluorescence } \\ \text { WT } & \text { wild type }\end{array}$

\section{Acknowledgments}

The authors thank Drs. Saburo Aimoto and Toru Kawakami (Institute for Protein Research, Osaka University, Japan) for their help with ITC measurements.

\section{REFERENCES}

1. Curtiss LK, Valenta DT, Hime NJ, Rye KA. What is so special about apolipoprotein AI in reverse cholesterol transport? Arterioscler Thromb Vasc Biol 2006;26:12-19. [PubMed: 16269660]

2. Rader DJ. Molecular regulation of HDL metabolism and function: implications for novel therapies. J Clin Invest 2006;116:3090-3100. [PubMed: 17143322]

3. Tall AR, Yvan-Charvet L, Terasaka N, Pagler T, Wang N. HDL, ABC transporters, and cholesterol efflux: implications for the treatment of atherosclerosis. Cell Metab 2008;7:365-375. [PubMed: 18460328]

4. Krimbou L, Marcil M, Genest J. New insights into the biogenesis of human high-density lipoproteins. Curr Opin Lipidol 2006;17:258-267. [PubMed: 16680030] 
5. Oram JF, Vaughan AM. ATP-Binding cassette cholesterol transporters and cardiovascular disease. Circ Res 2006;99:1031-1043. [PubMed: 17095732]

6. Chroni A, Liu T, Fitzgerald ML, Freeman MW, Zannis VI. Cross-linking and lipid efflux properties of apoA-I mutants suggest direct association between apoA-I helices and ABCA1. Biochemistry 2004;43:2126-2139. [PubMed: 14967052]

7. Vedhachalam C, Duong PT, Nickel M, Nguyen D, Dhanasekaran P, Saito H, Rothblat GH, Lund-Katz S, Phillips MC. Mechanism of ATP-binding cassette transporter A1-mediated cellular lipid efflux to apolipoprotein A-I and formation of high density lipoprotein particles. J Biol Chem 2007;282:2512325130. [PubMed: 17604270]

8. Hassan HH, Denis M, Lee DY, Iatan I, Nyholt D, Ruel I, Krimbou L, Genest J. Identification of an ABCA1-dependent phospholipid-rich plasma membrane apolipoprotein A-I binding site for nascent HDL formation: implications for current models of HDL biogenesis. J Lipid Res 2007;48:2428-2442. [PubMed: 17656736]

9. Segrest JP, Jones MK, De Loof H, Brouillette CG, Venkatachalapathi YV, Anantharamaiah GM. The amphipathic helix in the exchangeable apolipoproteins: a review of secondary structure and function. J. Lipid Res 1992;33:141-166. [PubMed: 1569369]

10. Palgunachari MN, Mishra VK, Lund-Katz S, Phillips MC, Adeyeye SO, Alluri S, Anantharamaiah GM, Segrest JP. Only the two end helixes of eight tandem amphipathic helical domains of human apo A-I have significant lipid affinity. Implications for HDL assembly. Arterioscler. Thromb. Vasc. Biol 1996;16:328-338. [PubMed: 8620350]

11. Saito H, Dhanasekaran P, Nguyen D, Deridder E, Holvoet P, Lund-Katz S, Phillips MC. $\alpha$-Helix formation is required for high affinity binding of human apolipoprotein A-I to lipids. J. Biol. Chem 2004;279:20974-20981. [PubMed: 15020600]

12. Wang L, Hua N, Atkinson D, Small DM. The N-terminal (1-44) and C-terminal (198-243) peptides of apolipoprotein A-I behave differently at the triolein/water interface. Biochemistry 2007;46:12140-12151. [PubMed: 17915945]

13. Fang Y, Gursky O, Atkinson D. Structural studies of N- and C-terminally truncated human apolipoprotein A-I. Biochemistry 2003;42:6881-6890. [PubMed: 12779343]

14. Tanaka M, Dhanasekaran P, Nguyen D, Ohta S, Lund-Katz S, Phillips MC, Saito H. Contributions of the $\mathrm{N}$ - and C-terminal helical segments to the lipid-free structure and lipid interaction of apolipoprotein A-I. Biochemistry 2006;45:10351-10358. [PubMed: 16922511]

15. Saito H, Dhanasekaran P, Nguyen D, Holvoet P, Lund-Katz S, Phillips MC. Domain structure and lipid interaction in human apolipoproteins A-I and E, a general model. J. Biol. Chem 2003;278:23227-23232. [PubMed: 12709430]

16. Silva RA, Hilliard GM, Fang J, Macha S, Davidson WS. A three-dimensional molecular model of lipid-free apolipoprotein A-I determined by cross-linking/mass spectrometry and sequence threading. Biochemistry 2005;44:2759-2769. [PubMed: 15723520]

17. Ajees AA, Anantharamaiah GM, Mishra VK, Hussain MM, Murthy HM. Crystal structure of human apolipoprotein A-I: insights into its protective effect against cardiovascular diseases. Proc. Natl. Acad. Sci. U. S. A 2006;103:2126-2131. [PubMed: 16452169]

18. Tanaka M, Koyama M, Dhanasekaran P, Nguyen D, Nickel M, Lund-Katz S, Saito H, Phillips MC. Influence of tertiary structure domain properties on the functionality of apolipoprotein A-I. Biochemistry 2008;47:2172-2180. [PubMed: 18205410]

19. Saito H, Lund-Katz S, Phillips MC. Contributions of domain structure and lipid interaction to the functionality of exchangeable human apolipoproteins. Prog. Lipid Res 2004;43:350-380. [PubMed: 15234552]

20. Davidson WS, Thompson TB. The structure of apolipoprotein A-I in high density lipoproteins. J Biol Chem 2007;282:22249-22253. [PubMed: 17526499]

21. Thomas MJ, Bhat S, Sorci-Thomas MG. Three dimensional models of high density lipoprotein apoAI:Implications for its assembly and function. J Lipid Res 2008;49:1875-1883. [PubMed: 18515783]

22. Davidson WS, Hazlett T, Mantulin WW, Jonas A. The role of apolipoprotein AI domains in lipid binding. Proc. Natl. Acad. Sci. U. S. A 1996;93:13605-13610. [PubMed: 8942981] 
23. Lagerstedt JO, Budamagunta MS, Oda MN, Voss JC. Electron paramagnetic resonance spectroscopy of site-directed spin labels reveals the structural heterogeneity in the N-terminal domain of apoA-I in solution. J Biol Chem 2007;282:9143-9149. [PubMed: 17204472]

24. Oda MN, Forte TM, Ryan RO, Voss JC. The C-terminal domain of apolipoprotein A-I contains a lipid-sensitive conformational trigger. Nat. Struct. Biol 2003;10:455-460. [PubMed: 12754494]

25. Gross E, Peng DQ, Hazen SL, Smith JD. A novel folding intermediate state for apolipoprotein A-I: role of the amino and carboxy termini. Biophys. J 2006;90:1362-1370. [PubMed: 16326917]

26. Tricerri MA, Behling Agree AK, Sanchez SA, Jonas A. Characterization of apolipoprotein A-I structure using a cysteine-specific fluorescence probe. Biochemistry 2000;39:14682-14691. [PubMed: 11087425]

27. Behling Agree AK, Tricerri MA, Arnvig McGuire K, Tian SM, Jonas A. Folding and stability of the C-terminal half of apolipoprotein A-I examined with a Cys-specific fluorescence probe. Biochim Biophys Acta 2002;1594:286-296. [PubMed: 11904224]

28. Fang Y, Gursky O, Atkinson D. Lipid-binding studies of human apolipoprotein A-I and its terminally truncated mutants. Biochemistry 2003;42:13260-13268. [PubMed: 14609337]

29. Chroni A, Liu T, Gorshkova I, Kan HY, Uehara Y, Von Eckardstein A, Zannis VI. The central helices of ApoA-I can promote ATP-binding cassette transporter A1 (ABCA1)-mediated lipid efflux. Amino acid residues 220-231 of the wild-type ApoA-I are required for lipid efflux in vitro and high density lipoprotein formation in vivo. J. Biol. Chem 2003;278:6719-6730. [PubMed: 12488454]

30. Beckstead JA, Block BL, Bielicki JK, Kay CM, Oda MN, Ryan RO. Combined N- and C-terminal truncation of human apolipoprotein A-I yields a folded, functional central domain. Biochemistry 2005;44:4591-4599. [PubMed: 15766290]

31. Sparks DL, Lund-Katz S, Phillips MC. The charge and structural stability of apolipoprotein A-I in discoidal and spherical recombinant high density lipoprotein particles. J. Biol. Chem 1992;267:25839-25847. [PubMed: 1464598]

32. Parasassi T, De Stasio G, Ravagnan G, Rusch RM, Gratton E. Quantitation of lipid phases in phospholipid vesicles by the generalized polarization of Laurdan fluorescence. Biophys J 1991;60:179-189. [PubMed: 1883937]

33. Saito H, Minamida T, Arimoto I, Handa T, Miyajima K. Physical states of surface and core lipids in lipid emulsions and apolipoprotein binding to the emulsion surface. J. Biol. Chem 1996;271:1551515520. [PubMed: 8663047]

34. Flora K, Brennan JD, Baker GA, Doody MA, Bright FV. Unfolding of acrylodan-labeled human serum albumin probed by steady-state and time-resolved fluorescence methods. Biophys $\mathbf{J}$ 1998;75:1084-1096. [PubMed: 9675210]

35. Sakamoto T, Tanaka M, Vedhachalam C, Nickel M, Nguyen D, Dhanasekaran P, Phillips MC, LundKatz S, Saito H. Contributions of the carboxyl-terminal helical segment to the self-association and lipoprotein preferences of human apolipoprotein E3 and E4 isoforms. Biochemistry 2008;47:29682977. [PubMed: 18201068]

36. Saito H, Dhanasekaran P, Baldwin F, Weisgraber KH, Lund-Katz S, Phillips MC. Lipid bindinginduced conformational change in human apolipoprotein E. Evidence for two lipid-bound states on spherical particles. J. Biol. Chem 2001;276:40949-40954. [PubMed: 11533033]

37. Monera OD, Kay CM, Hodges RS. Protein denaturation with guanidine hydrochloride or urea provides a different estimate of stability depending on the contributions of electrostatic interactions. Protein Sci 1994;3:1984-1991. [PubMed: 7703845]

38. Vedhachalam C, Liu L, Nickel M, Dhanasekaran P, Anantharamaiah GM, Lund-Katz S, Rothblat GH, Phillips MC. Influence of ApoA-I structure on the ABCA1-mediated efflux of cellular lipids. J. Biol. Chem 2004;279:49931-49939. [PubMed: 15383537]

39. Segall ML, Dhanasekaran P, Baldwin F, Anantharamaiah GM, Weisgraber KH, Phillips MC, LundKatz S. Influence of apoE domain structure and polymorphism on the kinetics of phospholipid vesicle solubilization. J. Lipid Res 2002;43:1688-1700. [PubMed: 12364553]

40. Krishnan R, Lindquist SL. Structural insights into a yeast prion illuminate nucleation and strain diversity. Nature 2005;435:765-772. [PubMed: 15944694] 
41. Sun Y, Breydo L, Makarava N, Yang Q, Bocharova OV, Baskakov IV. Site-specific conformational studies of prion protein (PrP) amyloid fibrils revealed two cooperative folding domains within amyloid structure. J Biol Chem 2007;282:9090-9097. [PubMed: 17244617]

42. Kono M, Okumura Y, Tanaka M, Nguyen D, Dhanasekaran P, Lund-Katz S, Phillips MC, Saito H. Conformational flexibility of the N-terminal domain of apolipoprotein a-I bound to spherical lipid particles. Biochemistry 2008;47:11340-11347. [PubMed: 18831538]

43. Krasnowska EK, Gratton E, Parasassi T. Prodan as a membrane surface fluorescence probe: partitioning between water and phospholipid phases. Biophys J 1998;74:1984-1993. [PubMed: 9545057]

44. Davidson WS, Arnvig-McGuire K, Kennedy A, Kosman J, Hazlett TL, Jonas A. Structural organization of the N-terminal domain of apolipoprotein A-I: studies of tryptophan mutants. Biochemistry 1999;38:14387-14395. [PubMed: 10572013]

45. Beckstead JA, Wong K, Gupta V, Wan CP, Cook VR, Weinberg RB, Weers PM, Ryan RO. The C terminus of apolipoprotein A-V modulates lipid-binding activity. J Biol Chem 2007;282:1548415489. [PubMed: 17401142]

46. Wong K, Beckstead JA, Lee D, Weers PM, Guigard E, Kay CM, Ryan RO. The N-terminus of apolipoprotein A-V adopts a helix bundle molecular architecture. Biochemistry 2008;47:8768-8774. [PubMed: 18652480]

47. Krishna MM, Englander SW. The N-terminal to C-terminal motif in protein folding and function. Proc. Natl. Acad. Sci. U. S. A 2005;102:1053-1058. [PubMed: 15657118]

48. Hatters DM, Budamagunta MS, Voss JC, Weisgraber KH. Modulation of apolipoprotein E structure by domain interaction: differences in lipid-bound and lipid-free forms. J Biol Chem 2005;280:3428834295. [PubMed: 16076841]

49. Bhat S, Sorci-Thomas MG, Alexander ET, Samuel MP, Thomas MJ. Intermolecular contact between globular N-terminal fold and C-terminal domain of ApoA-I stabilizes its lipid-bound conformation: studies employing chemical cross-linking and mass spectrometry. J Biol Chem 2005;280:3301533025. [PubMed: 15972827]

50. Dong LM, Weisgraber KH. Human apolipoprotein E4 domain interaction. Arginine 61 and glutamic acid 255 interact to direct the preference for very low density lipoproteins. J Biol Chem 1996;271:19053-19057. [PubMed: 8702576]

51. Saito H, Dhanasekaran P, Baldwin F, Weisgraber KH, Phillips MC, Lund-Katz S. Effects of polymorphism on the lipid interaction of human apolipoprotein E. J. Biol. Chem 2003;278:4072340729. [PubMed: 12917433]

52. Narayanaswami V, Wang J, Schieve D, Kay CM, Ryan RO. A molecular trigger of lipid bindinginduced opening of a helix bundle exchangeable apolipoprotein. Proc. Natl. Acad. Sci. USA 1999;96:4366-4371. [PubMed: 10200268]

53. Lu B, Morrow JA, Weisgraber KH. Conformational reorganization of the four-helix bundle of human apolipoprotein E in binding to phospholipid. J Biol Chem 2000;275:20775-20781. [PubMed: 10801877]

54. Morrow JA, Hatters DM, Lu B, Hochtl P, Oberg KA, Rupp B, Weisgraber KH. Apolipoprotein E4 forms a molten globule. A potential basis for its association with disease. J. Biol. Chem 2002;277:50380-50385. [PubMed: 12393895]

55. Guha M, Gao X, Jayaraman S, Gursky O. Correlation of structural stability with functional remodeling of high-density lipoproteins: the importance of being disordered. Biochemistry 2008;47:1139311397. [PubMed: 18839964]

56. Weers PM, Kay CM, Ryan RO. Conformational changes of an exchangeable apolipoprotein, apolipophorin III from Locusta migratoria, at low $\mathrm{pH}$ : correlation with lipid binding. Biochemistry 2001;40:7754-7760. [PubMed: 11412130]

57. Weers PM, Abdullahi WE, Cabrera JM, Hsu TC. Role of buried polar residues in helix bundle stability and lipid binding of apolipophorin III: destabilization by threonine 31. Biochemistry 2005;44:88108816. [PubMed: 15952787]

58. Weers PM, Narayanaswami V, Choy N, Luty R, Hicks L, Kay CM, Ryan RO. Lipid binding ability of human apolipoprotein E N-terminal domain isoforms: correlation with protein stability? Biophys Chem 2003;100:481-492. [PubMed: 12646385] 
59. Fukuda M, Nakano M, Miyazaki M, Tanaka M, Saito H, Kobayashi S, Ueno M, Handa T. Conformational change of apolipoprotein A-I and HDL formation from model membranes under intracellular acidic conditions. J Lipid Res 2008;49:2419-2426. [PubMed: 18645209]

60. Hatters DM, Howlett GJ. The structural basis for amyloid formation by plasma apolipoproteins: a review. Eur Biophys J 2002;31:2-8. [PubMed: 12046894]

61. Uversky VN, Fink AL. Conformational constraints for amyloid fibrillation: the importance of being unfolded. Biochim Biophys Acta 2004;1698:131-153. [PubMed: 15134647]

62. Sorci-Thomas MG, Thomas MJ. The effects of altered apolipoprotein A-I structure on plasma HDL concentration. Trends Cardiovasc Med 2002;12:121-128. [PubMed: 12007737]

63. Genschel J, Haas R, Propsting MJ, Schmidt HH. Apolipoprotein A-I induced amyloidosis. FEBS Lett 1998;430:145-149. [PubMed: 9688527]

64. Liz MA, Gomes CM, Saraiva MJ, Sousa MM. ApoA-I cleaved by transthyretin has reduced ability to promote cholesterol efflux and increased amyloidogenicity. J Lipid Res 2007;48:2385-2395. [PubMed: 17693625] 


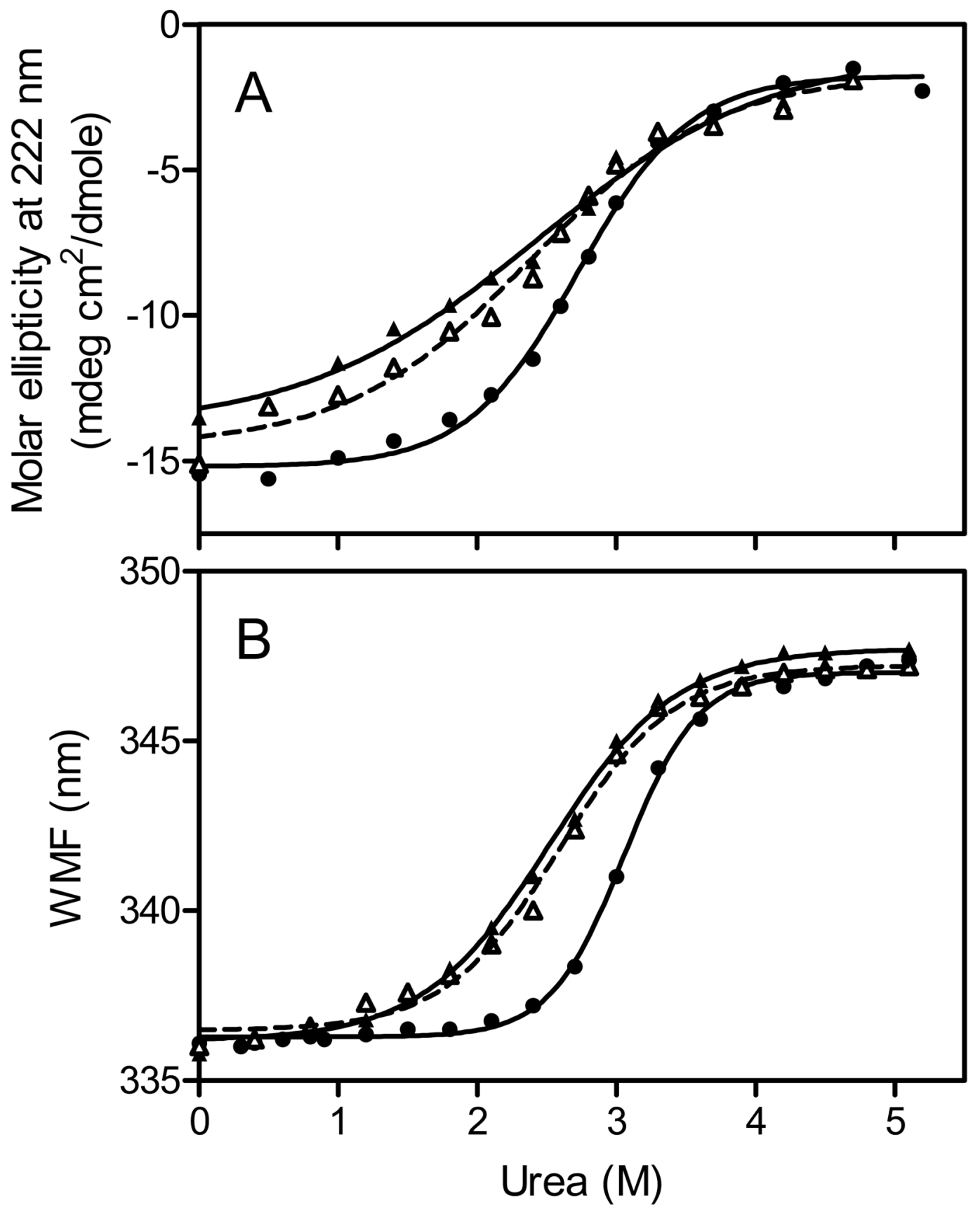

Figure 1.

Urea-induced denaturation of human and mouse hybrid apoA-I monitored by molar ellipticity (A) or Trp fluorescence (B). $\bullet$, human WT; $\boldsymbol{\Lambda}$, apoA-I h(1-189)/m(187-240); $\Delta$, apoA-I h $(1-220) / \mathrm{m}(218-240)$. Protein concentration was $50 \mu \mathrm{g} / \mathrm{ml}$. 

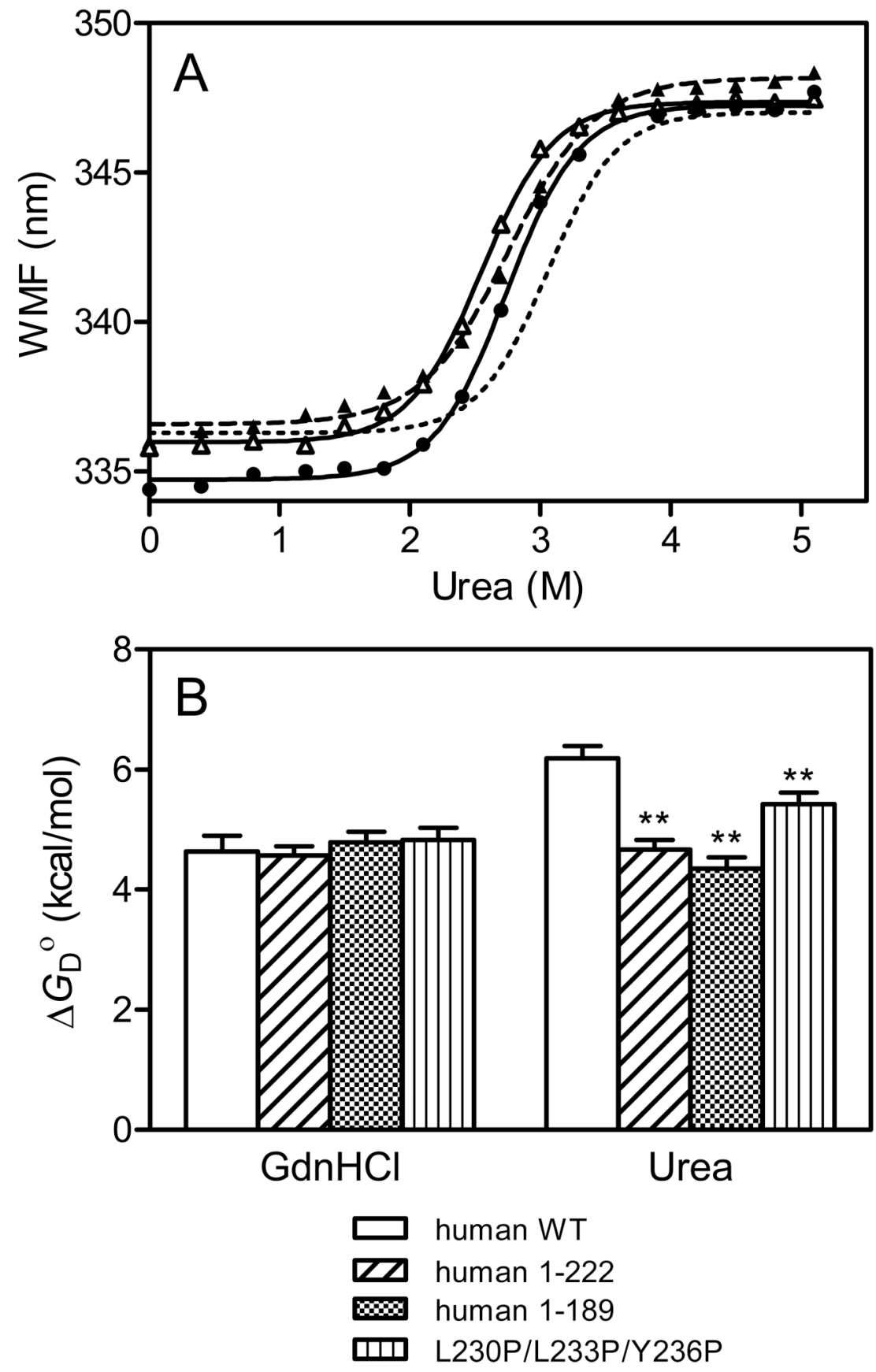

Figure 2.

Chemical denaturation of the C-terminal-truncated human apoA-I mutants monitored by Trp fluorescence. (A) Urea-induced denaturation of human WT (dotted line), human 1-222 $(\Delta$ ), human 1-189 ( $\mathbf{\Delta}$ ), and human L230P/L233P/Y236P (•). Protein concentration was $25 \mu \mathrm{g} / \mathrm{ml}$. (B) Comparison of the free energies of denaturation induced by $\mathrm{GdnHCl}$ and urea. $* * P<0.01$ compared to human WT apoA-I $\left(\Delta G_{\mathrm{D}}{ }^{\circ}\right.$ in $\mathrm{GdnHCl}$ and urea denaturation are $4.6 \pm 0.3$ and 6.2 $\pm 0.2 \mathrm{kcal} / \mathrm{mol}$, respectively). 

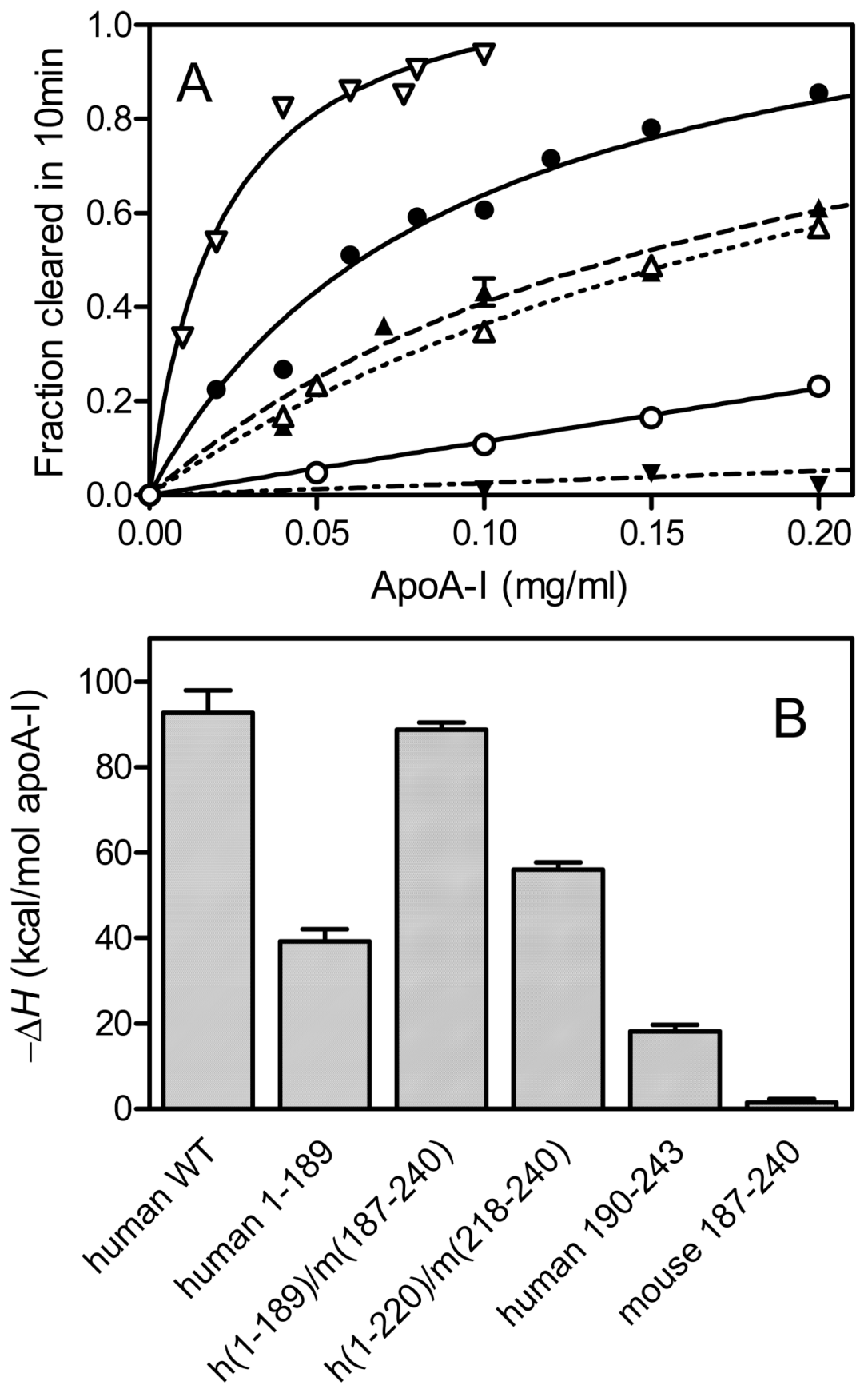

Figure 3.

Solubilization of DMPC vesicles (A) and binding enthalpies to egg PC SUV (B) for human and mouse hybrid apoA-I. (A) Increase in fraction cleared of turbidity in 10 min after incubation of DMPC vesicles $(0.25 \mathrm{mg} / \mathrm{mL})$ with increasing concentration of protein at $24.6{ }^{\circ} \mathrm{C}$. $\bullet$, human WT; ○, human 1-189; $\boldsymbol{\Delta}$, apoA-I h(1-189)/m(187-240); $\Delta$, apoA-I h(1-220)/m(218-240); $\nabla$, human 190-243; $\boldsymbol{\nabla}$, mouse 187-240. (B) Protein solutions were injected into excess SUV in an isothermal titration calorimeter at a PC-to-protein molar ratio of $>10,000$. 


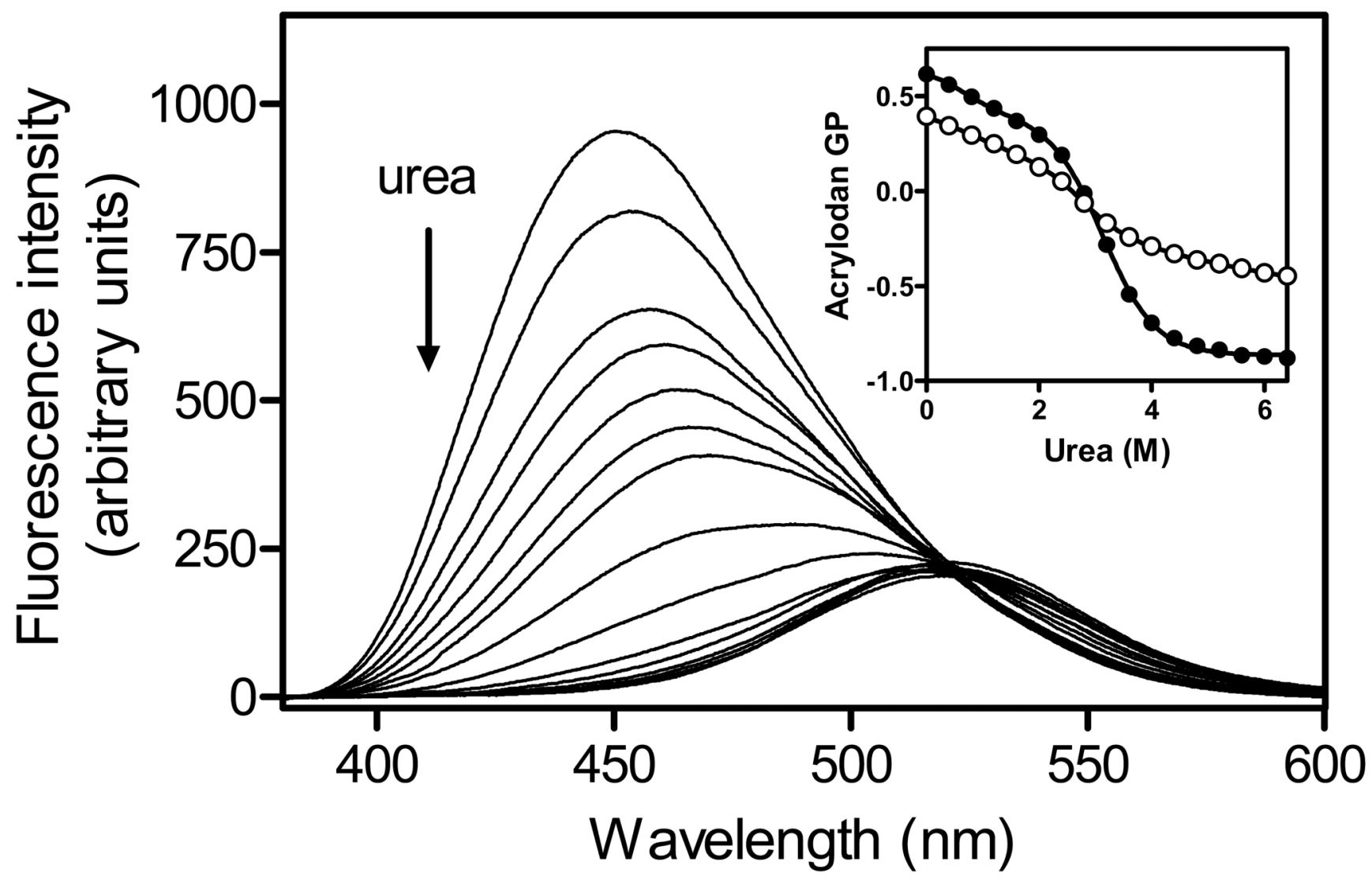

Figure 4.

Acrylodan fluorescence emission spectra monitored at different concentrations of urea (from 0 to $6.4 \mathrm{M}$ ) for apoA-I V53C-Ac. The inset shows the change in acrylodan GP for apoA-I V53C-Ac $(\bullet)$ and F229C-Ac ( $(0)$ as a function of urea concentration. Protein concentration was $25 \mu \mathrm{g} / \mathrm{ml}$. 

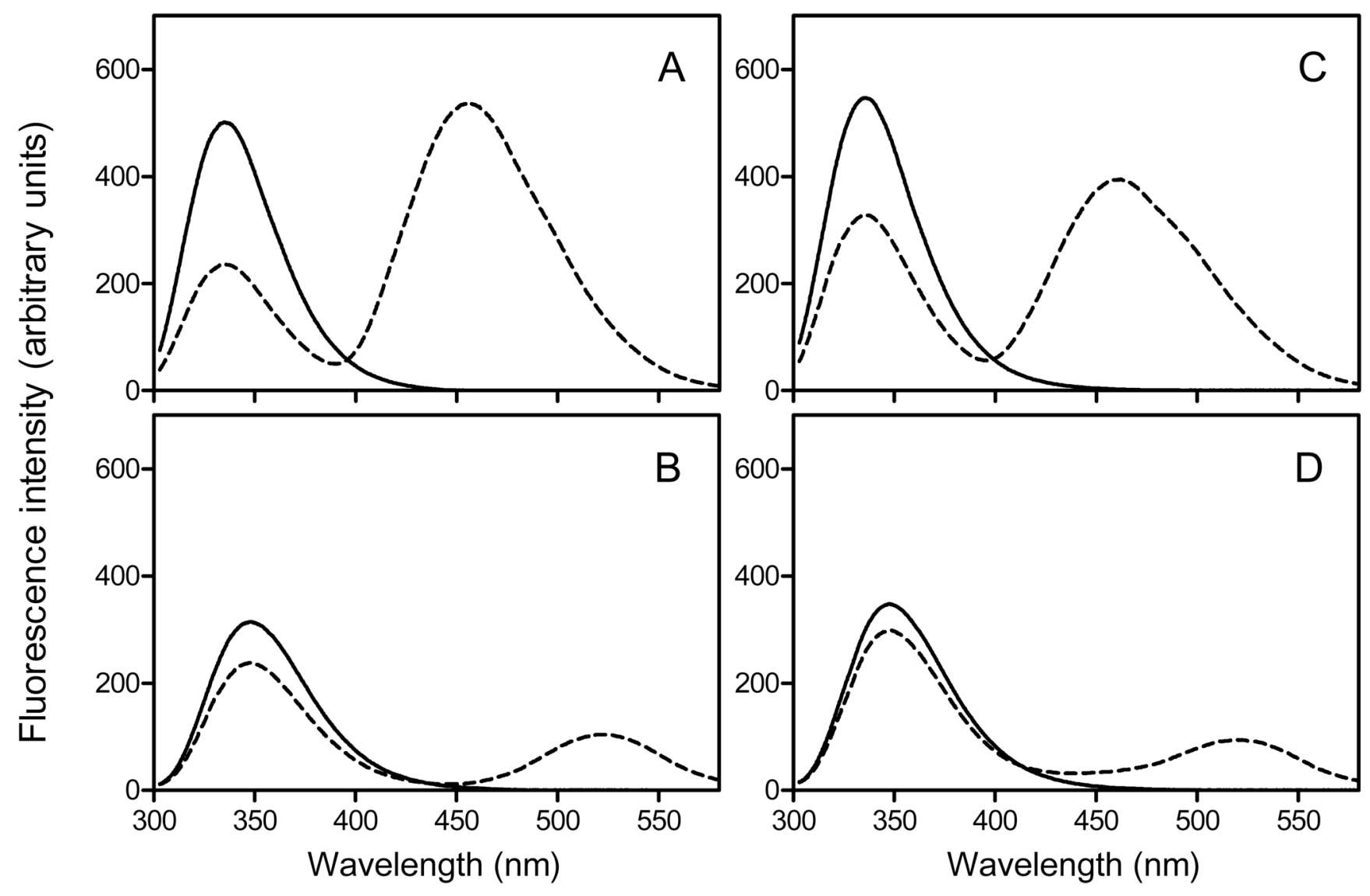

Figure 5.

FRET between Trp residues in the N-terminal domain and acrylodan for apoA-I V53C-Ac (A and B) and F229C-Ac (C and D). Fluorescence emission spectra excited at $295 \mathrm{~nm}$ for unlabeled (solid lines) and acrylodan-labeled (dashed lines) apoA-I variants were recorded in the absence (A and C) or presence (B and D) of $3 \mathrm{M} \mathrm{GdnHCl}$. Protein concentration was 25 $\mu \mathrm{g} / \mathrm{ml}$. 


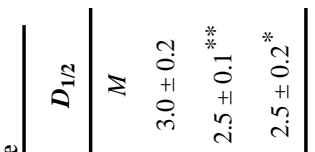

흥

苞

ษ

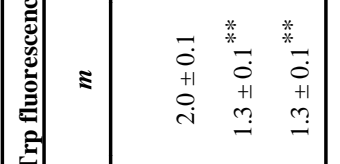


Table 2

Parameters of KI Quenching of Trp Fluorescence and ANS Binding of ApoA-I Variants

\begin{tabular}{lccc}
\hline \multirow{2}{*}{ apoA-I variant } & \multicolumn{2}{c}{ KI quenching } & \\
\cline { 2 - 3 } & $f_{\mathbf{a}}$ & $\boldsymbol{K}_{\mathbf{S V}}$ & \\
\hline & & $M^{-1}$ & \\
human WT & $0.67 \pm 0.03$ & $4.7 \pm 0.3$ & 1.0 \\
human $1-189$ & $0.67 \pm 0.02$ & $6.0 \pm 0.2^{* *}$ & 0.6 \\
human $1-222$ & $0.64 \pm 0.02$ & $5.7 \pm 0.2^{* *}$ & 0.6 \\
$\mathrm{~h}(1-189) / \mathrm{m}(187-240)$ & $0.65 \pm 0.02$ & $5.7 \pm 0.3^{* *}$ & 0.8 \\
$\mathrm{~h}(1-220) / \mathrm{m}(218-240)$ & $0.67 \pm 0.02$ & $5.2 \pm 0.2^{*}$ & 0.8 \\
\hline
\end{tabular}

${ }^{a}$ Values are relative to WT. Estimated error is within \pm 0.1 .

${ }^{*} P<0.05$

** $P<0.01$ compared to WT apoA-I 


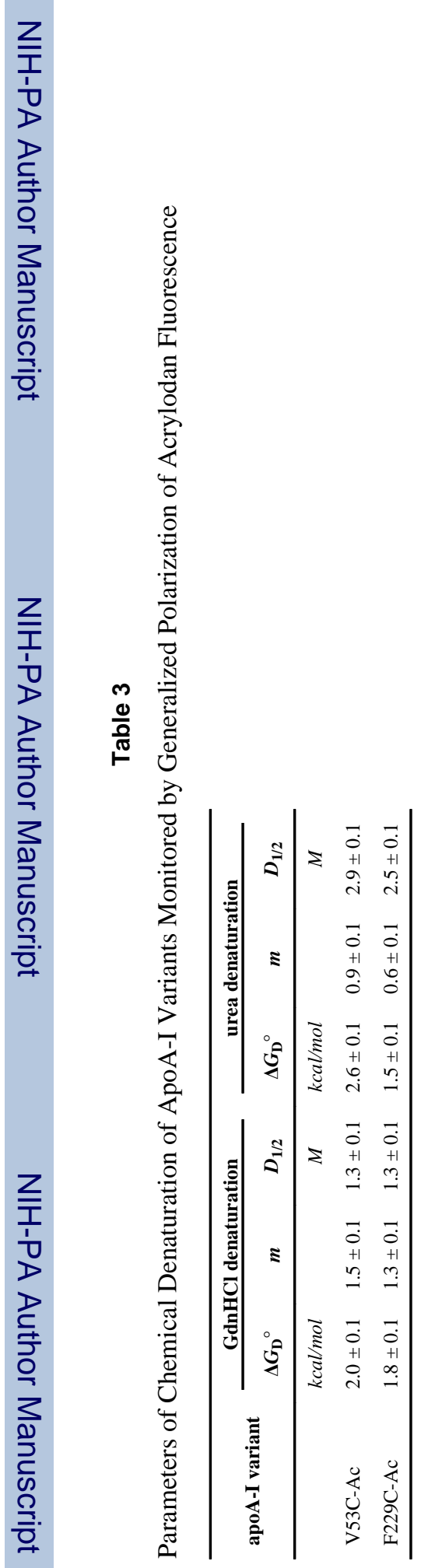

Biochemistry. Author manuscript; available in PMC 2010 September 10. 


\section{Table 4}

WMF, Fluorescence Anisotropy, and KI Quenching Parameters of Acrylodan fluorescence of ApoA-I Variants and Peptide

\begin{tabular}{|c|c|c|c|c|}
\hline \multirow{2}{*}{ apoA-I variant or peptide } & \multirow{2}{*}{$\mathrm{WMF}^{a}$} & \multirow{2}{*}{$\begin{array}{l}\text { fluorescence } \\
\text { anisotropy }\end{array}$} & \multicolumn{2}{|c|}{ KI quenching } \\
\hline & & & $f_{\mathrm{a}}$ & $K_{\mathrm{SV}}$ \\
\hline & $n m$ & & & $M^{-1}$ \\
\hline apoA-I V53CA-c & 451 & $0.152 \pm 0.002$ & $0.73 \pm 0.05$ & $3.1 \pm 0.3$ \\
\hline apoA-I F229C-Ac & 460 & $0.140 \pm 0.002$ & $0.51 \pm 0.04$ & $3.7 \pm 0.4$ \\
\hline apoA-I 220-241/F229C-Ac & 516 & $0.086 \pm 0.004$ & $0.60 \pm 0.04$ & $11.5 \pm 0.6$ \\
\hline
\end{tabular}

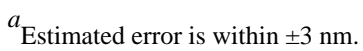

